\title{
Impact of Post-Harvest Biomass Burning on Aerosol Characteristics and Radiative Forcing over Patiala, North-West region of India
}

\author{
Deepti Sharma, Manjit Singh, and Darshan Singh* \\ Department of Physics, Punjabi University, Patiala, Punjab (India)-147002
}

\begin{abstract}
The present study deals with impact of post-harvest biomass burning on aerosol characteristics over Patiala (Lat: $30.33^{\circ} \mathrm{N}$; Long: $76.4^{\circ} \mathrm{E}$ ), Punjab state, India during 2008-09, using ground based and satellite data. Results of Aerosol Optical Depth (AOD) measurements using MICROTOPS II show significant variations with highest $\mathrm{AOD}_{500} \approx 2.65$ in October 2008 and $\approx 1.71$ in November 2009. The maximum monthly mean values of angstrom parameters " $\alpha$ " and " $\beta$ " are $1.13 \pm 0.16$ and $0.39 \pm 0.20$, respectively. Daily averaged values of Black Carbon (BC) mass concentration during day time show significant variations $\left(8-18 \mu \mathrm{g} / \mathrm{m}^{3}\right)$ yielding SSA varying from 0.76-0.88 during highly turbid days and 0.95-0.97 during less turbid days. During highly turbid days, the estimated atmospheric radiative forcing using SBDART varies from +43.0 to $+86.5 \mathrm{Wm}^{-2}$ suggesting high $\mathrm{BC}$ concentration in the atmosphere associated with paddy residue burning in the fields.
\end{abstract}

\section{Introduction}

Atmospheric aerosols perturb the radiation budget of the Earth-atmosphere system through radiative forcing thereby affecting the climate (Charlson et al., 1992, Chang and Song., 2010). Aerosols are, generally believed to exert cooling effect on the Earth's climate and potentially offsetting the global warming caused by greenhouse gases (Boucher and Haywood, 2001). However, cooling or warming by aerosols depends upon their optical properties and underlying surface albedo. Scattering aerosols such as sulphates backscatter the down-welling solar radiation and indirectly change the cloud albedo resulting in cooling of the atmosphere (Charslon et al., 1992). On the other hand, soot particles such as black carbon (BC) are highly absorbing type aerosols that absorb the solar radiation leading to heating of the atmosphere (Jacobson, 2001). The major source of soot aerosols are fossil fuel combustion, forest fires and biomass burning. Optical properties of soot particles depend on the combustion temperature along with other carbonaceous particles emitted during combustion processes (Bond and Bergstorm, 2006). Smoke particles from biomass burning have direct radiative impact by scattering and absorbing short wave radiation and indirect radiative impact by serving as cloud condensation nuclei that change the cloud microphysical and optical properties (Cattani et al., 2005).

North-west region of India comprising Punjab, Haryana and Uttar Pradesh is dominated by wheat-rice crop rotation and harvesting of these crops is mostly done with combine harvesters leaving behind large quantities of straw in the fields. The wheat residue after harvesting is used for animal feed contributing little to the pollution but the rice stubble being unfit for animal feed is burned in the open fields emitting trace gases as well as sub-micron particles posing health hazard to the local habitants (Badrinath et al., 2006). During the months of October and 
November each year, Punjab state is engulfed with a vast cloud of smoke due to burning of the rice stubble leading to high aerosol loading and significantly reducing the visibility.

The aim of the present study is to examine the impact of paddy residue burning on the aerosol characteristics and to estimate their effect on radiative balance of Earth-Atmosphere system on regional scale over Patiala city; Punjab state (India) using ground based measurements. The aerosol optical depth (AOD) measurements using a Multi-Wavelength Radiometer (MWR) and aerosol mass concentration by High Volume Sampler were started at the Punjabi University Campus, Patiala (30.33 N, 76.4 E, 249 m a.s.l) in April 2006 (Manjit et al., 2008) under ISROGeosphere Biosphere Programme (IGBP). Later on, black carbon (BC) observations using aethalometer and additional AOD measurements by MicrotopII sunphotometer were started in January 2008 and October 2008 respectively. In this paper, we present the results on various physical and optical parameters of aerosols inferred from continuous measurements made over Patiala during the months of October and November for the years 2008 and 2009 and discussed the impact of biomass burning on the radaitve forcing over the region.

\section{Site description and Meteorology}

Patiala city of Punjab state, being at the centre of the agrarian region of northwest India, is situated on NH 64 at about $60 \mathrm{~km}$ southwest from foothills of Shivalik range and about $200 \mathrm{~km}$ northeast of Thar Desert. It is surrounded by industrial and polluted cities like Ludhiana $(90 \mathrm{~km})$ and Gobindgarh $(40 \mathrm{~km})$ in the northwest and Ambala $(50 \mathrm{~km})$ in the east. On the basis of meteorological conditions prevailing over the site, whole year has been divided in to four seasons viz. winter (December-March), pre-monsoon (April-June), monsoon (July-September) and postmonsoon (October-November). Extreme weather conditions prevail over the region as summer is very hot and dry while winter is very cold. The Punjab state suffers from frequent dust storms during May-June due to south-westerly winds coming from Thar Desert side (Sikka D.R., 1997) and severe fog, haze and smog during winter due to anthropogenic activities (Singh et al., 2004). The climate of the region is significantly affected by the occasional occurrence of western disturbances entering northwest India from Pakistan side resulting in rain over the plains and snow fall over the hills during winter and pre-monsoon seasons. During the study period (October-November) weather is mainly dry with average daytime relative humidity varying from $40-70 \%$, moderate temperature ranging from $20-30^{\circ} \mathrm{C}$ and slow westerly wind ranges between 1 $2 \mathrm{~ms}^{-1}$ (Fig.1).

\section{Methodology}

\section{Aerosol Optical Depth}

Aerosol optical depth (AOD) measurements are made using a handheld multichannel MICROTOPS II sun photometer of Solar Light Company, USA (Porter et al., 2001, Morys et al., 2001). This instrument simultaneously measures AOD at five wavelengths viz. 380, 440, 500, $675,870 \mathrm{~nm}$ with each filter having narrow bandwidth of around $10 \mathrm{~nm}$. The spectral variation of AOD can be characterized using Ångström relation (Ångström 1964) expressed as 


$$
\tau_{\lambda}=\beta . \lambda^{-\alpha}
$$

Where $\tau_{\lambda}$ is the AOD at wavelength $\lambda$, " $\beta$ " is known as turbidity parameter and " $\alpha$ " is the angstrom exponent that depends on the size distribution of aerosols. The Ångström formula assumes that Jung's power law (Junge., 1955) is valid for all types of aerosols which is not true (Tomasi et al., 1983; King and Byrne., 1976). Thus equation (1) is a special case of a more complicated law valid for a limited range of particles diameter and limited intervals of wavelength. The validation of this theory supposes that the Junge's power law is valid for some limited cases of particle radius range where the significant extinction take place and the spectral variation of refractive index do not impose significant variations on Mie extinction factor (Kaskaoutis et al., 2007). Taking the logarithm of both sides of Eq. (1) obtains:

$$
\ln \tau_{\lambda}=-\alpha \ln \lambda+\ln \beta
$$

Using (2) the angstrom exponent can be computed from spectral values of AOD as:

$$
\alpha=-\frac{d \ln \tau_{\lambda}}{d \ln \lambda}=-\frac{\ln \left(\frac{\tau_{\lambda_{2}}}{\tau_{\lambda_{1}}}\right)}{\ln \left(\frac{\lambda_{2}}{\lambda_{1}}\right)}
$$

Dubovik et al. (2002) has also confirmed that instead of following Junge power law, the retrieved size distribution of all type of aerosols exhibit bimodal distribution. The departure of this relationship introduces curvature into the $\ln \tau_{\lambda}$ versus $\ln \lambda$ relationship, it means the logarithm of (1) is not a straight line anymore and the linear fit of $\ln \tau_{\lambda}$ versus $\ln \lambda$ shows significant deviation from measured AOD whereas the second order polynomial fit to $\ln \tau_{\lambda}$ versus $\ln \lambda$ is in good agreement with measured AOD (Eck et al., 1999). The second order polynomial equation is given by:

$$
\ln \tau_{\lambda}=a_{2} \ln \lambda^{2}+a_{1} \ln \lambda+a_{0}
$$

where $\alpha$ terms are constants and the coefficient $a_{2}$ accounts for curvature often observed in Sun photometry measurements. The negative value of curvature indicates that the aerosol-size distribution is dominated by fine mode particles and positive value of curvature indicates the dominance of coarse mode particles (Eck et al., 1999). The second order polynomial fit (Eq. 4) was applied to AOD values at six wavelengths $(380,440,500,675,800,870 \mathrm{~nm})$. Though the polynomial fit to Eq. (4) is more precise than the linear fit to Eq. (2) but it is prone to errors especially under low turbidity conditions. Hence, only those cases of second order polynomial fit having $\mathrm{R}^{2}>0.99$ were considered to minimize the errors (Sharma et al., 2010).

\section{Black Carbon Mass Concentration}

Black carbon (BC) measurements were carried out using seven channels Aethalometer (Model AE-21, Magee Scientific, USA). It provides the real time readout of concentration of black or elemental carbon aerosol particles in an air stream. As the air passes through the quartz fiber 
filter tape for a fixed amount of time $(5 \mathrm{~min})$ with a selected constant flow rate $\left(3.5 \mathrm{~L} \mathrm{~m}^{-1}\right.$ in the present case), aerosols get deposited on it. When the light beam is transmitted through the aerosols deposited continuously on the fiber filter tape, the attenuation of light beam is measured at seven different wavelength viz. 370, 470, 520, 590, 660, 880, $950 \mathrm{~nm}$ (Hansen et al., 1984). Out of these seven wavelengths, $880 \mathrm{~nm}$ is considered as standard wavelength for BC measurement as BC is only the major aerosol species which act as a good absorber at this wavelength. The absorption coefficient is calculated from the difference in light transmission through the aerosol deposited spot and aerosol free spot as reference which is converted into equivalent $\mathrm{BC}$ mass concentration using factory set wavelength dependent calibration factors (Pathak et al., 2010). The overall uncertainty in BC mass concentration including shadowing effect does not exceed 20\% (Babu et al., 2002).

\section{Optical properties $(O P A C)$}

The software package OPAC (Optical Properties of Aerosols and Clouds) is used to estimate the optical properties of aerosols over the sampling site, Patiala (Hess al., 1998) taking a mixture of five aerosol types as externally mixed spherical particles forming the composite aerosols. These are insoluble, water-soluble, BC (soot), mineral (accumulation mode) and mineral transported. Fixing the $\mathrm{BC}$ mass mixing ratio (ratio of the mass concentration of $\mathrm{BC}$ to the total mass of the composite aerosols), the number densities of other components are varied. A number of iterations are performed so that the estimated AOD and angstrom wavelength exponent are in good agreement with the observed values (Babu et al., 2002). This model permits eight values of relative humidity $(0 \%, 50 \%, 70 \%, 80 \%, 90 \%, 95 \%, 98 \%$ and $99 \%)$ which play an important role for reconstruction of AOD and we used the value closest to the mean relative humidity during the study period. Various optical parameters such as single scattering albedo (SSA), asymmetry parameter $(\mathrm{g})$ and phase function $(\mathrm{P}(\theta))$ of this model are computed using OPAC as a function of wavelength ranging from 0.25 to $4.0 \mu \mathrm{m}$.

\section{Aerosol Radiative Forcing (SBDART)}

The aerosol radiative forcing is the change in the short-wave solar radiation flux either at the surface or at the top of the atmosphere without and with aerosols particles in the atmosphere (Russel et al., 1999, Babu et al., 2002). This can be estimated using SBDART code developed by University of California, Santa Barbara for the analysis of radiative transfer problems arising in atmospheric energy budget studies and remote sensing (Ricchiazzi et al., 1998) and is based upon various physical models which are well tested and reliable. It computes parallel plane radiative transfer in clear and cloudy conditions within the earth's atmosphere and at the surface. The observed values of aerosol optical depth (AOD) and angstrom exponent $(\alpha)$ and estimated values of single scattering albedo (SSA), asymmetry parameter (g) using OPAC software package are used as an input to SBDART to compute aerosol radiative forcing at the surface and top of the atmosphere (TOA). The surface albedo is calculated using MODIS albedo product (MODIS/Terra + Aqua albedo 16-day L3 global $1 \mathrm{~km}$ SIN Grid V005) which provides both white-sky albedo (WSA) as well as black-sky albedo (BSA) for MODIS bands ranging from $0.645-2.13 \mu \mathrm{m}$. Using WSA and BSA the actual surface albedo has been calculated. The surface albedo used in the present study is $0.15 \pm 0.06$. The atmospheric radiative forcing is the difference between surface radiative forcing (SRF) and the radiative forcing at the top of the atmosphere (TOA). 


\section{Results and discussion}

Spectral AOD measurements were made using a MicrotopII sun photometer on hourly basis for a clear or partial cloudy day and averaging of hourly values provide one data set of spectral AOD for the whole day. Figure 2a-b show day to day variability of spectral AOD during October and November for the years 2008 and 2009. There is a gradual increase in the AOD values more significantly at shorter wavelengths (380-500nm) as compared to longer wavelengths in the first half of October 2008 (Fig 2a) suggesting additional loading of submicron aerosols over the region as the crop residue burning activity picks up during this period. AOD values reaches to its peak value (3.2 at $380 \mathrm{~nm}$ ) at the end of October followed by a decrease approaching to a minimum (with few exceptions depending on weather conditions) in the second half of November when the burning process of straw in the fields almost ceases. The sudden decrease of AOD around $16^{\text {th }}$ of October 2008 is due to occurrence of rain during the night of 15th October that led to temporarily halting the burning of paddy residue as it became wet and partly due to scavenging of aerosols by precipitation resulting in significant decrease of aerosol loading. The overall values of AOD during the study period of 2009 are lower as compared to that of year 2008 indicating comparatively less biomass burning. The monthly mean $\mathrm{AOD}_{500 \mathrm{~nm}}$ exhibited smaller values during $2009(0.64 \pm 0.25)$ as compared to $2008(0.81 \pm 0.41)$. This may be attributed partly to the use of newly developed straw cutting machines by farmers and the awakening of farmers about the adverse effects of straw burning on the soil and human health thus discouraging them to adopt open burning in the fields.

The Angstrom exponent " $\alpha$ " and turbidity parameter " $\beta$ " estimated from the AOD values using the least square method over the range of $380-870 \mathrm{~nm}$ are shown in figure 3a-b.There is a systematic increase in the value of " $\alpha$ " from 0.9 to 1.4 towards end of October during both the years indicating increase of accumulation mode of particles with increase of biomass burning activity. Similar trend has been observed in the turbidity parameter " $\beta$ " suggesting more turbid atmospheric conditions during the study period. Figure 4a-b shows scatter plots of the coefficient $a_{2}$ (measure of curvature in the polynomial fit) versus $\mathrm{AOD}_{500 \mathrm{~nm}}$ during Post monsoon for the years 2008 and 2009. The correlation between $a_{2}$ and $\mathrm{AOD}_{500 \mathrm{~nm}}$ infer about the atmospheric conditions under which the " $\alpha$ " is independent of wavelength (Sharma et al., 2010). The data points lying on or near the $a_{2}=0$ line corresponds to bimodal log-normal aerosol size distribution without curvature while negative $a_{2}$ values indicates the presence of fine mode aerosols and positive $a_{2}$ values correspond to coarse mode aerosols in the atmosphere (Kaskaoutis et al., 2007). It is evident from the plots that most of the $a_{2}$ values lies below the $a_{2}=0$ line indicating the abundance of fine mode particles during biomass burning period. A comparison of $a_{2}$ values during Post monsoon with Pre monsoon season (Fig. 4c) show majority of $a_{2}$ values above $a_{2}=0$ line during Pre monsoon season indicating the presence of coarse mode particles transported by south westerly winds from Thar Desert over the region (Sikka D.R., 1997).

The suspended particulate matter (SPM) measured with high volume sampler that separates respire-able suspended particulate matter (RSPM) from coarse particles of size more than 10 microns (NRSPM) plotted in figure 5a-b exhibit higher concentration of RSPM (150-300 $\left.\mu \mathrm{gm} / \mathrm{m}^{3}\right)$ than NRSPM $\left(50-180 \mu \mathrm{gm} / \mathrm{m}^{3}\right)$ during Oct-Nov 2008. However, there is almost similar increase of RSPM $\left(70-200 \mu \mathrm{gm} / \mathrm{m}^{3}\right)$ along with NRSPM $\left(50-240 \mu \mathrm{gm} / \mathrm{m}^{3}\right)$ during 2009 but less loading as compared to the previous year consistent with spectral AOD observations over the study period. The diurnal variation of $\mathrm{BC}$ mass concentration measured with aethalometer during 
the Post monsoon season is shown in figure 6a-b for the years 2008 and 2009. Diurnal variation of BC mass concentration shows a maximum $\left(\approx 13-18 \mu \mathrm{g} / \mathrm{m}^{3}\right)$ around 0900 hours and a minimum $\left(\approx 4-7 \mu \mathrm{g} / \mathrm{m}^{3}\right)$ around 1500 hours for both the years. Morning maximum is attributed to the shallow atmospheric boundary layer leading to accumulation of soot particles. However, with passage of time, the solar heating of the earth's surface increases the mixing height of the boundary layer causing the dispersion of the pollutants and hence a minimum in $\mathrm{BC}$ mass concentration is observed.

Aerosol optical parameters such as single scattering albedo (SSA) and asymmetry parameter (g) are obtained by using AOD data measured with MicrotopsII sun photometer as input to OPAC model (Hess et al., 1998). Figure 7a-b shows the variation of single scattering albedo (SSA) versus wavelength for both low and highly turbid days. The SSA value at shorter wavelengths are higher (0.95-0.97) during less turbid days than highly turbid days (0.76-0.88) suggesting the abundance of absorbing type aerosols over scattering type aerosols during highly turbid days. The SSA is wavelength dependent and decreases with wavelength during the study period. Aerosol radiative forcing at any location depends upon several parameters such as aerosol loading, their vertical distribution, SSA, their size distribution, scattering phase function, underlying surface albedo, relative humidity in the atmosphere, solar insolation and various other factors (Haywood and Boucher, 2000). The radiative forcing calculations over the study site were made using radiative transfer model SBDART (Ricchiazzi et al., 1998). The observed values of spectral AOD and Angstrom exponent " $\alpha$ " along with estimated values of SSA and asymmetry parameter were used as input to the SBDART to estimate the clear sky short wave (SW) radiative forcing for few cases of low and high turbid days. The estimated values of SW radiative forcing at the surface (SRF), TOA and atmosphere (ATM) for low and high turbid days are given in Table 1 and are also plotted in Fig.8. The surface raditive forcing is negative in all the cases and varies from -13.9 to $-17.2 \mathrm{Wm}^{-2}$ for low turbid days and from -57.2 to $-96.9 \mathrm{Wm}^{-2}$ for high turbid days. The magnitude of TOA forcing is small as compared to surface forcing and is mostly negative with one exception during the study period. It ranges between -7.02 to $-9.9 \mathrm{Wm}^{-2}$ for low turbid days and between -14.13 to $0.17 \mathrm{Wm}^{-2}$ during turbid days. The difference between the TOA and SRF is the atmospheric forcing. The atmospheric forcing varies from 6.1 to $9.9 \mathrm{Wm}^{-2}$ for low turbid days while its magnitude is much higher ( 43.0 to $86.5 \mathrm{~W} \mathrm{~m}^{-2}$ ) during high aerosol loading days. The high values of atmospheric radiative forcing during the crop residue burning period may result in heating of the atmosphere that can have impact on the climate at the regional level.

\section{Conclusions}

The impact of agriculture residue burning on aerosol properties over Patiala in the IGP region of India has been investigated during post-monsoon season. Higher values of AOD at shorter wavelengths, " $\alpha$ " and " $\beta$ " exhibited during the crop residue burning period suggests increased concentration of accumulation mode particles in the atmosphere. The AOD values are higher during the year 2008 compared to 2009 and are attributed to more intense crop residue burning during 2008.

Aerosol mass concentration RSPM and NRSPM show significant day to day variations and higher concentration of RSPM is due to BC emissions during biomass burning. Similarly black carbon concentration $\left(\mathrm{BC}\right.$ ) has high values ranging from $4-18 \mu \mathrm{g} / \mathrm{m}^{3}$ during the study period and 
show significant diurnal variations. Single scattering albedo (SSA) is low during high turbid days suggesting abundance of absorbing aerosols (BC) due to emissions from biomass burning. There is increased atmospheric forcing during the crop residue burning period that may have its percussions on the regional climate.

\section{Acknowledgements}

The present work was carried out under ISRO-GBP (ARFI) project. The authors are thankful to ISRO for providing the financial support under the project.

\section{REFERENCES}

[1] Ångström A., The parameters of atmospheric turbidity, Tellus, 16, 64-75, 1964.

[2] Boucher O., and Haywood J., On summing the components of radiative forcing of climate change, Clim. Dynam., 18, 297-302, 2001.

[3] Babu S. S., Satheesh S. K., and Moorthy K. K., Aerosol radiative forcing due to enhanced black carbon at an urban site in India, Geophys. Res. Lett., 29(18), 1880, doi: 10.1029/2002GL015826, 2002.

[4] Badarinath, K. V. S., Chand T. R. K., and Prasad V. K., Agriculture crop residue burning in the Indo-Gangetic plains - A study using IRS P6 AWiFS satellite, Current Sci., 91, 1085-1089, 2006.

[5] Bond T. C. and Bergstrom R. W., Light Absorption by Carbonaceous Particles: An Investigative Review, Aerosol Sci. Technol., 40, 27-67, 2006.

[6] Charlson R. J., Schwartz S. E., Hales J. M., Cess R. D., Coakley J.A., Hansen J. E., and Hoffmann D. J., Climate forcing by anthropogenic aerosols, Science, 255, 423-430, 1992.

[7] Cattani E., Costa M. J., Torricella F., Levizzani V., and Silva A. M., Influence of aerosol particles from biomass burning on cloud microphysical properties and radiative forcing, Atmos. Res., 82, 310-327, 2005.

[8] Chang D., Song Y., Estimates of biomass burning emissions in tropical Asia based on satellite derived data, Atmos. Chem. Phys., 10, 2335-2351, 2010.

[9] Dubovik O., Smirnov A., Holben B. N., King M. D., Kaufman Y. J., Eck T. F., and Slutsker I., Accuracy assessments of aerosol properties retrieved from Aerosol Robotic Network (AERONET) sun and sky radiance measurements, J. Geophys. Res., 105, 9791-9806, 2000.

[10] Eck T. F., Holben B. N., Reid J. S., Dubovic O., Smirnov A., O’Neil N. T., Slutsker I. and Kinne S., Wavelength dependence of the optical depth of biomass burning, urban, and desert dust aerosols, J. Geophys. Res., 104, 31333-31349, 1999. 
[11] Hansen A. D. A., Rosen H., and Novakov T., The Aethalometer- An Instrument for the realtime measurement of optical absorption by aerosol particles, Sci. Total Environ., 36, 191-196, 1984.

[12] Haywood J. N., and Boucher O., Estimates of the direct and indirect radiative forcing due to tropospheric aerosols: A review, Rev. Geophys., 38, 513-543, 2000.

[13] Junge C. E., The size distribution and aging of natural aerosols as determined from electrical and optical measurements in the atmosphere, J. Meteorol., 12, 13-25, 1955.

[14] Jacobson M. Z., Strong radiative due to the mixing state of black carbon in the atmospheric aerosols, Nature, 409, 695-697, 2001.

[15] Hess M., Koepke P., and Schultz I., Optical properties of aerosols and clouds: The software package OPAC, Bull. Am. Meteorol. Soc., 79, 831-844, 1998.

[16] King M. D. and Byrne D. M., A method for inferring total ozone content from spectral variation of total optical depth obtained with a solar radiometer, J. Atmos. Sci., 33, 22422251, 1976.

[17] Kaskaoutis D. G., Kambezidis H. D., Hatzianastassiou N., Kosmopoulos P. G. and Badarinath K. V. S., Aerosol climatology: dependence of the Angstrom exponent on wavelength over four AERONET sites, Atmos. Chem. Phys. Discuss., 7, 7347-7397, 2007.

[18] http://www.atmos-chem-phys-discuss.net/7/7347/2007/.

[19] Morys M., Mims F. M., Hagerup S., Anderson S. E., Baker A., Kia J., and Walkup T., Design, calibration and performance of Microtops II handheld ozone monitor and Sun photometer. J. Geophys. Res., 106:14573-14582, 2001.

[20] Singh M., Singh D., and Pant P., Aerosol characteristics at Patiala during ICARB- 2006, J. Earth Sys. Sci. 117, S1, 407-411, 2008.

[21] Porter J. N., Miller M., Pietras C., Mottel C., Ship based sunphotometer measurements using Microtops Sun Photometers, J. Atms. and Oce. Tech., 18, 2001.

[22] Pedr'os R., Martinez-Lozano J. A., Utrillas M. P., G'omez-Amo J. L. and Tena F., Column-integrated aerosol, optical properties from ground-based spectroradiometer measurements at Barrax (Spain) during the Digital Airborne Imaging Spectrometer Experiment, 2003.

[23] (DAISEX) campaigns. J. Geophys. Res., 108, D18, 4571-4587.

[24] Pathak B., Kalita G., Bhuyan K., Bhuyan P. K., and Moorthy K. K., Aerosol temporal characteristics and its impact on shortwave radiative forcing at a location in the northeast of India, J. Geophys. Res., 115, D19204, doi:10.1029/2009JD013462, 2010.

[25] Ricchiazzi P., Yang S., Gautier C., and Sowle D., SBDART: A research and teaching software tool for plane parallel radiative transfer in the Earth's atmosphere, Bull. Am. Meteorol. Soc., 79, 2101-2114, 1998. 
[26] Russell L.M., Seinfeld J. H., Flagan R. C., Ferek R. J., Hegg D. A., Hobbs P. V., Wobrock W., Flossmann A., O'Dowd C. D., Nielsen K. E., and Durkee P. A.,: Aerosol Dynamics in Ship Tracks, J. Geophys. Res., 104: 31,077-31,096, 1999.

[27] Sikka D. R., Desert climate and its dynamics, Curr. Sci., 72(1), 35-46, 1997.

[28] Singh R. P., Dey S., Tripahi S. N., and Tare V., J. Geophys. Res., 109, D2306, doi: 10.1029/2004JD004966, 2004.

[29] Sharma A. R., Kharol S. K., Badrinath K. V. S. and Singh D., Impact of agriculture crop burning on atmospheric aerosol loading-a study over Punjab State, India, Ann. Geophys., 28, 367-379, 2010.

[30] Tomasi C., Caroli E. and Vitale V., Study of the relationship between Ångström's wavelength exponent and Junge particle size distribution exponent, J. Clim. Appl. Meteorol., 22, 1707-1716, 1983. 


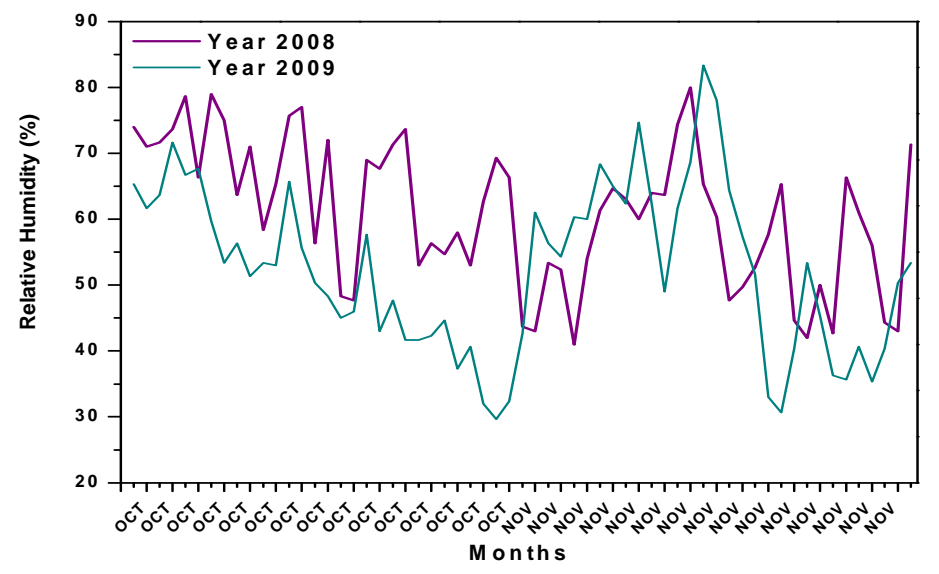

(a)

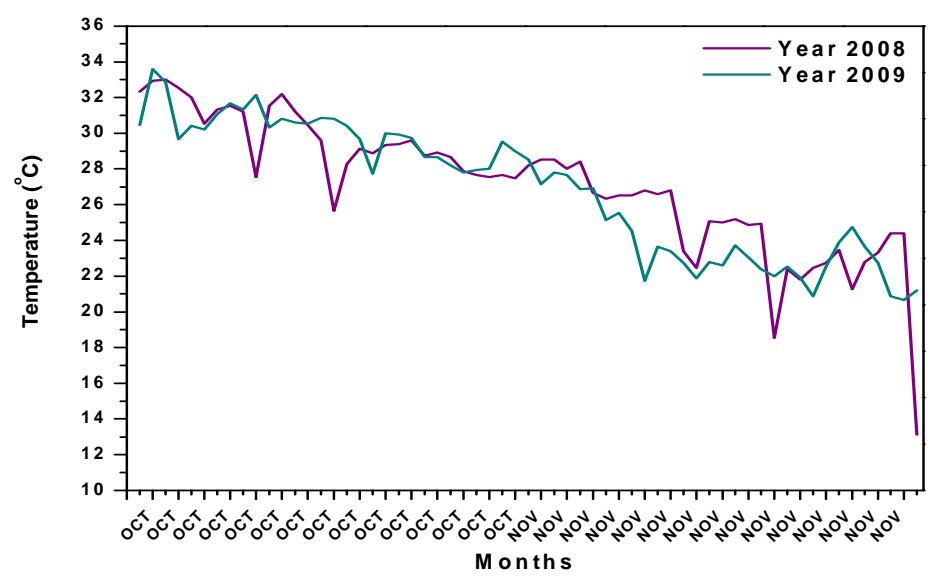

(b)

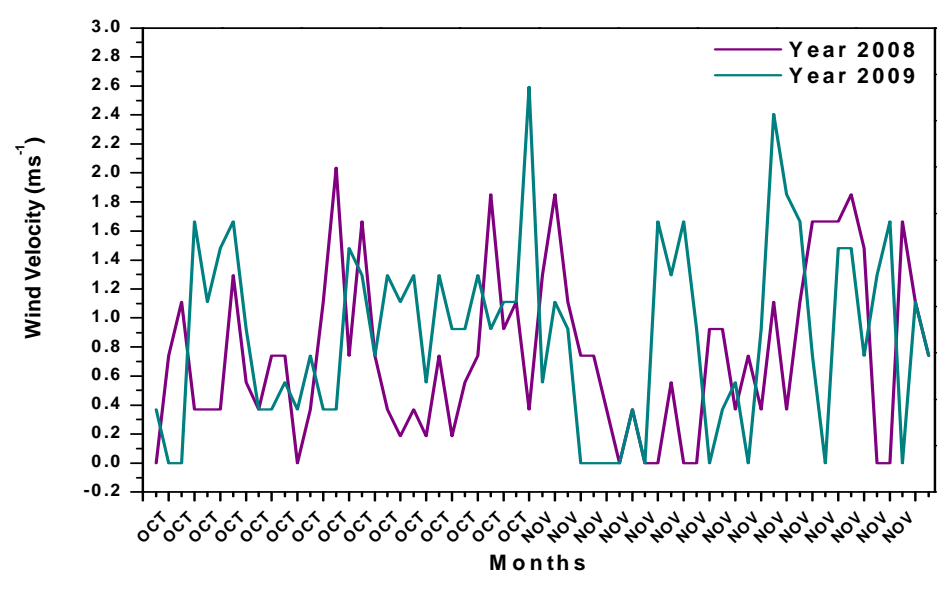

(c)

Figure 1a-c: Day to day variation of averaged Meteorological parameters 


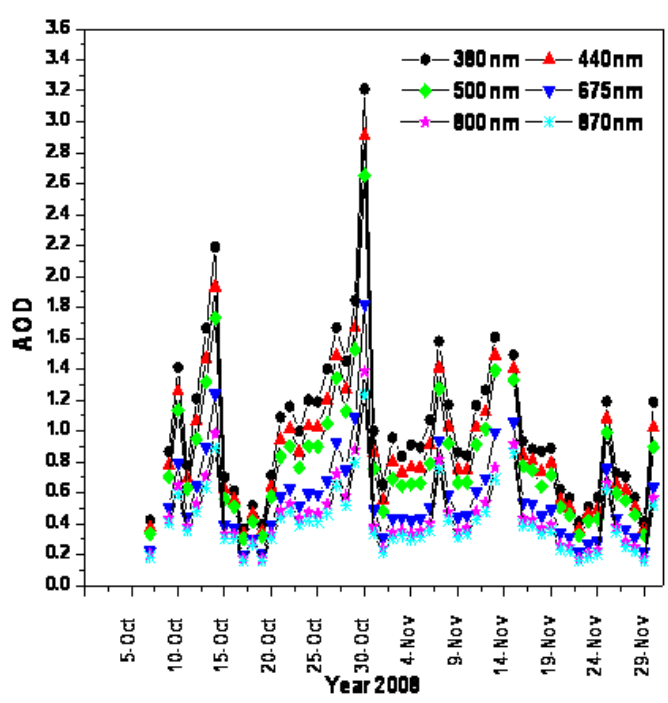

(a)

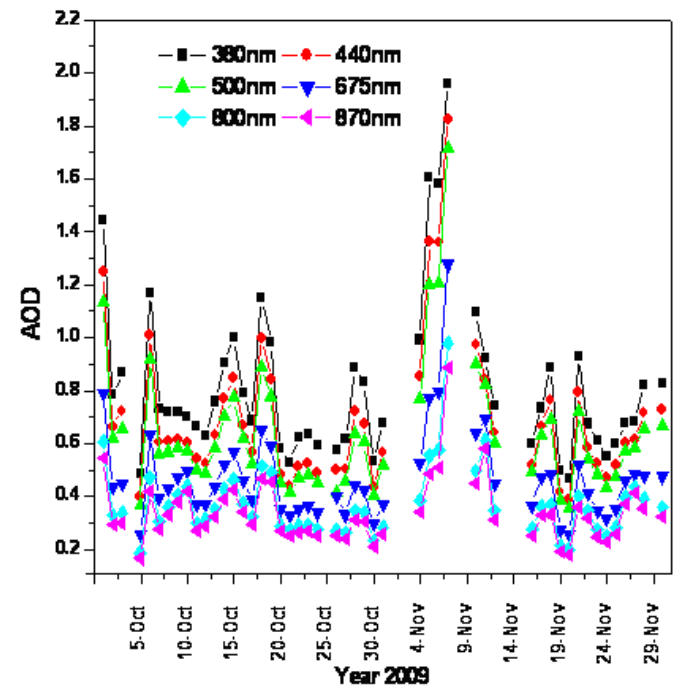

(b)

Figure 2 a-b: Day to day variation of spectral AOD

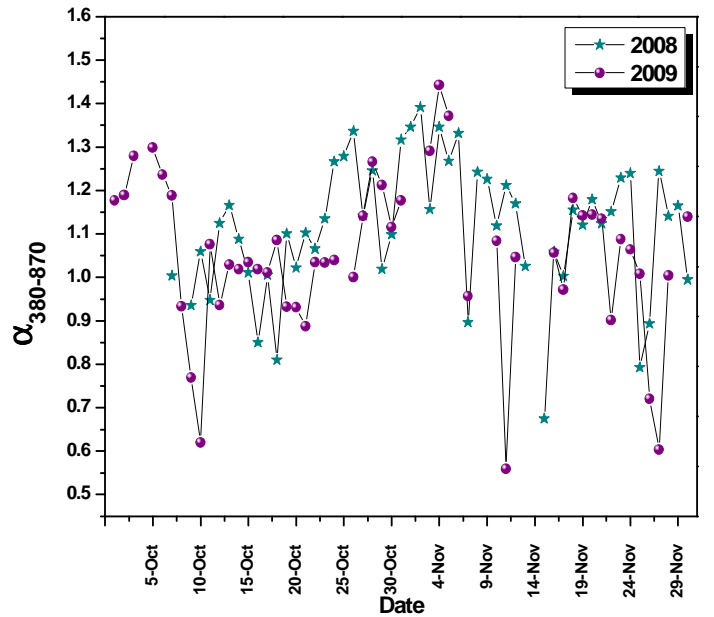

(a)

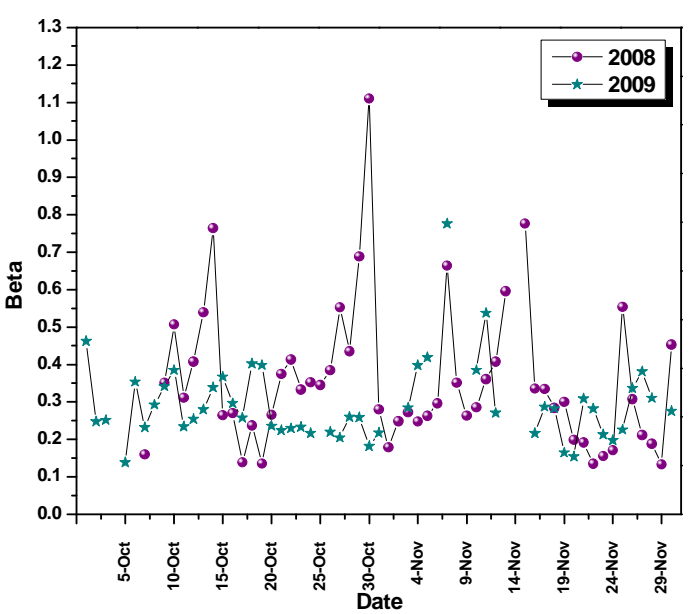

(b)

Figure 3 a-b: Day to day variation of Angstrom coefficients 


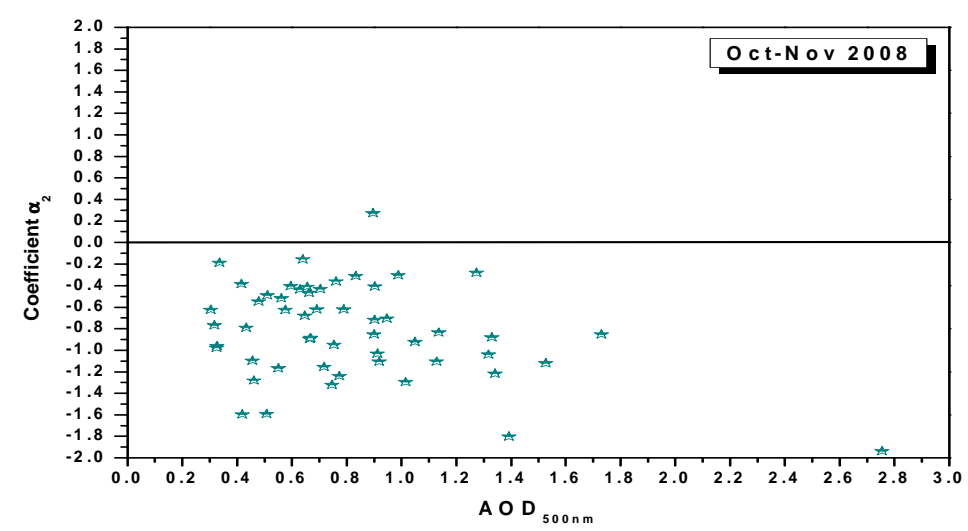

(a)

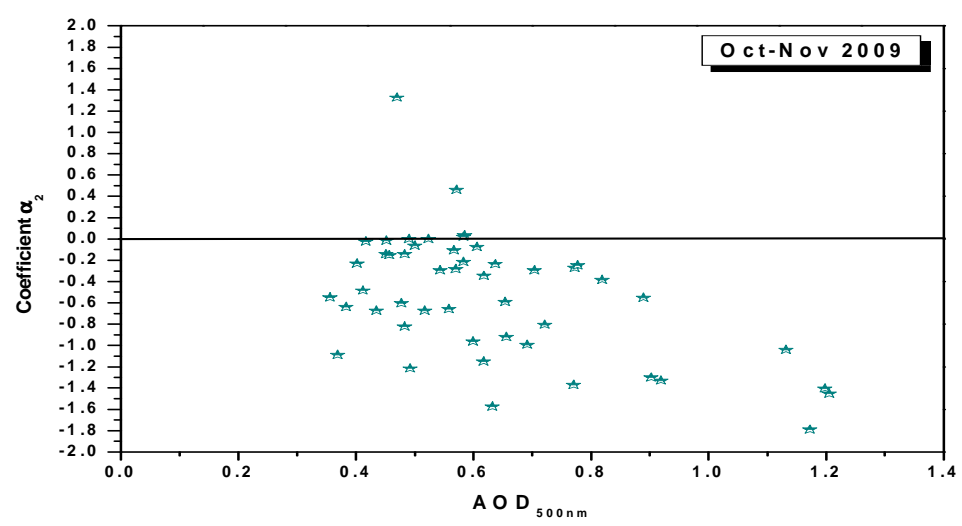

(b)

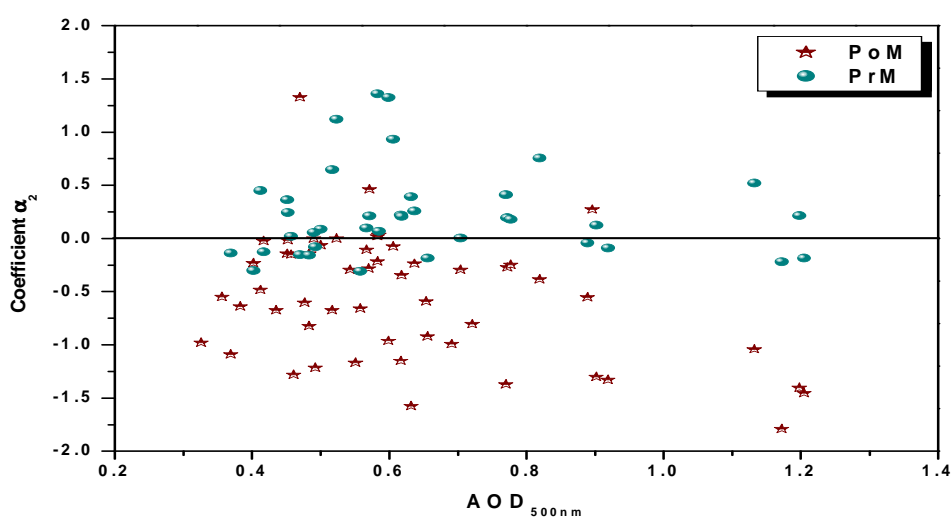

(c)

Figure 4 a-c: Scatter plot of coefficient a2 versus AOD500nm during post-monsoon (PoM) (a) year 2008, (b) year 2009 and also with pre monsoon (PrM) (c) year 2009 


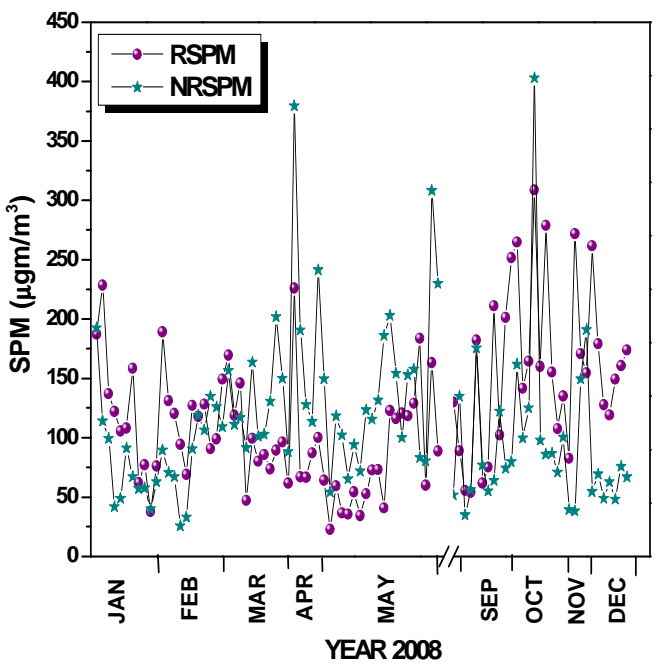

(a)

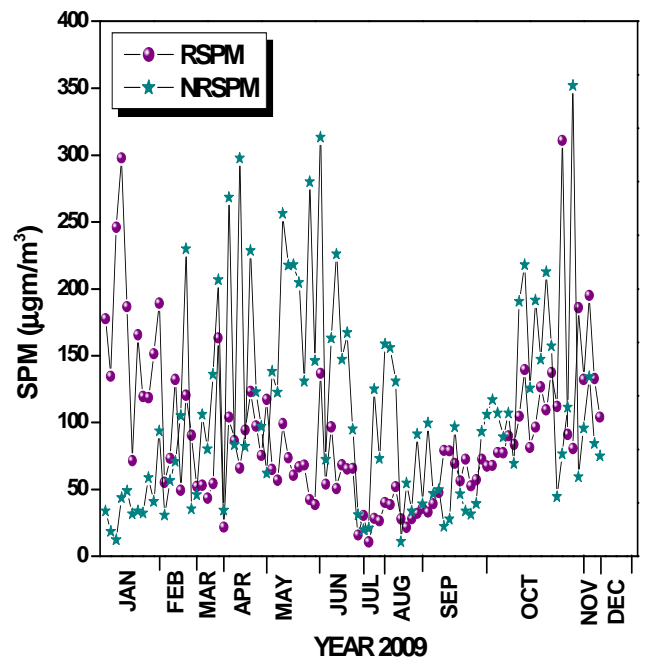

(b)

Figure 5 a-b: Day to day variation of RSPM and NRSPM (a) year 2008 and (b) year 2009

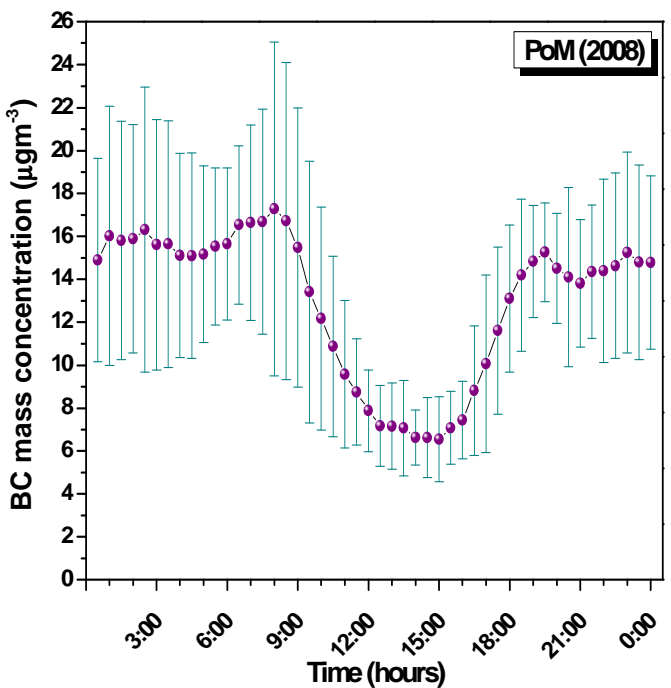

(a)

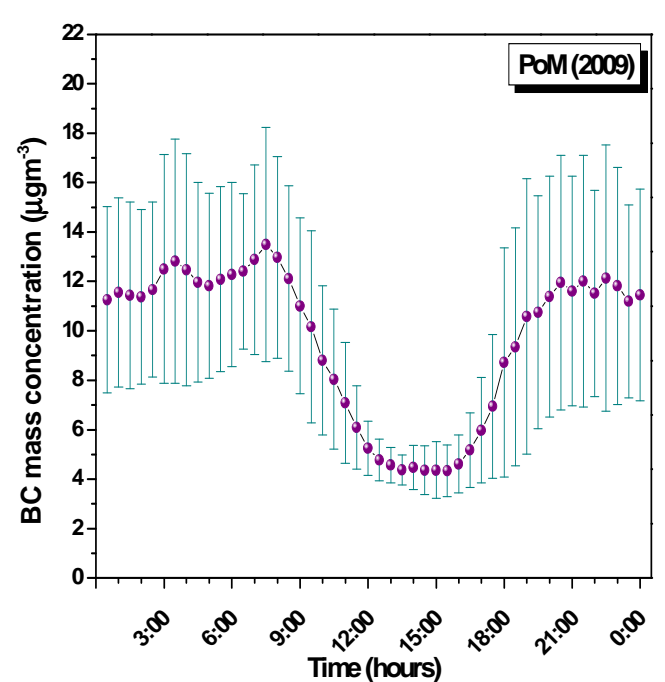

(b)

Figure 6 a-b: Diurnal variation of BC mass concentration during PoM (a) year 2008 and (b) year 2009 


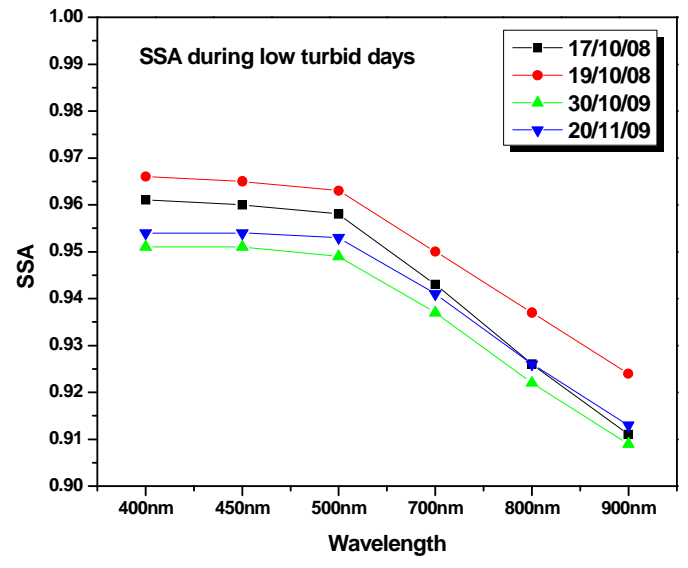

(a)

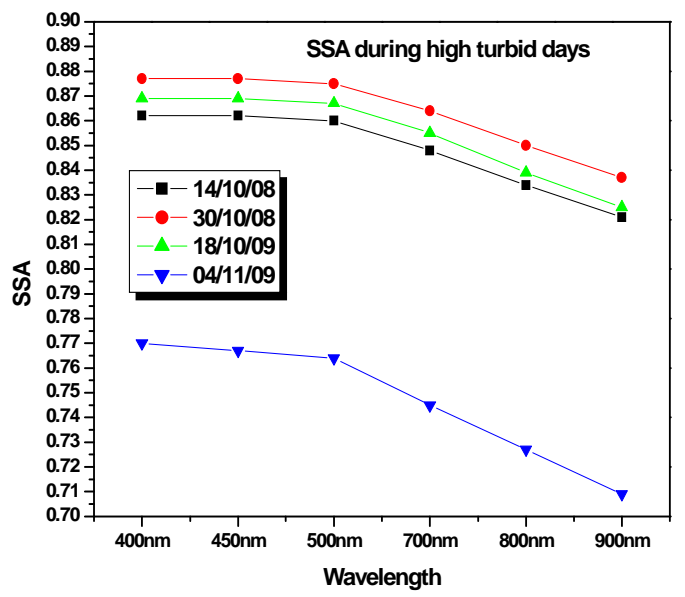

(b)

Figure 7 a-b: Variation of SSA versus wavelength during (a) low and (b) high turbid days

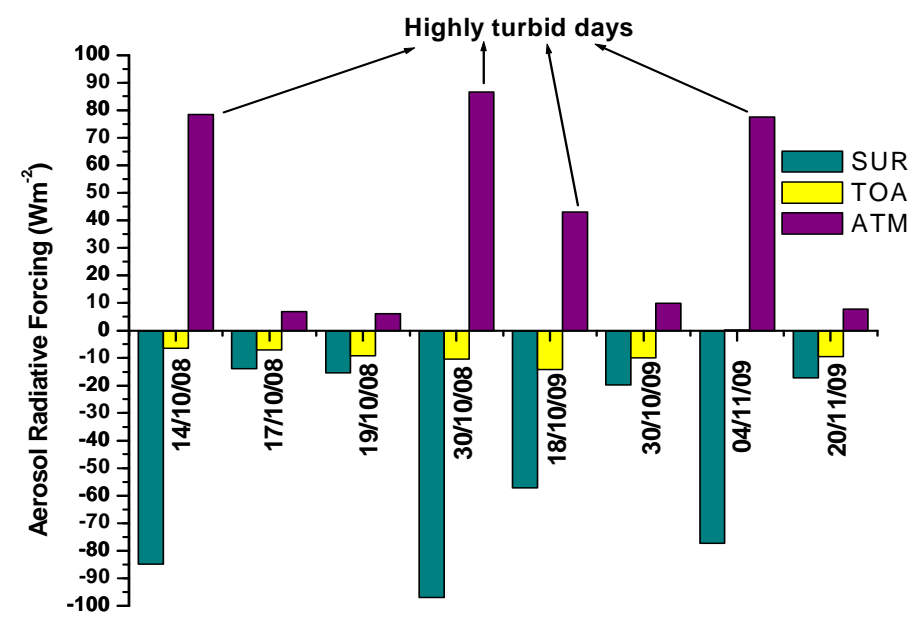

Figure 8: Aerosol SW radiative forcing over Patiala during low and high turbid days

Table 1: SW radiative forcing (Wm-2) during low and high turbid days

\begin{tabular}{|c|c|c|c|c|c|c|c|c|}
\hline & \multicolumn{4}{|c|}{ Low turbid days } & \multicolumn{4}{c|}{ High turbid days } \\
\hline Date & $17 / 10 / 08$ & $19 / 10 / 08$ & $30 / 10 / 09$ & $20 / 11 / 09$ & $14 / 10 / 08$ & $30 / 10 / 08$ & $18 / 10 / 09$ & $04 / 11 / 09$ \\
\hline SRF & -13.91 & -15.30 & -19.87 & -17.24 & -84.77 & -96.98 & -57.22 & -77.31 \\
\hline TOA & -7.02 & -9.10 & -9.94 & -9.55 & -6.42 & -10.45 & -14.13 & +0.17 \\
\hline ATM & +6.89 & +6.19 & +9.92 & +7.69 & +78.35 & +86.52 & +43.09 & +77.48 \\
\hline
\end{tabular}

